\title{
ANÁLISE DE PERCEPÇÕES ACERCA DOS PONTOS POSITIVOS E NEGATIVOS DO USO DE IDENTIFICAÇÃO POR RADIOFREQUÊNCIA EM BIBLIOTECAS: UM ESTUDO DE CASO
}

\section{ARTGO ORIGINAL}

LIMA, Diego Andrade Velloso de ${ }^{1}$, MEIRIÑOS, Marcelo Jasmim²

LIMA, Diego Andrade Velloso de. MEIRIÑOS, Marcelo Jasmim. Análise de percepções acerca dos pontos positivos e negativos do uso de identificação por radiofrequência em bibliotecas: um estudo de caso. Revista Científica Multidisciplinar Núcleo do Conhecimento. Ano 06, Ed. 08, Vol. 05, pp. 104-124. Agosto de 2021. ISSN: 2448-0959, Link de acesso: https://www.nucleodoconhecimento.com.br/tecnologia/radiofrequencia-embibliotecas, DOI: 10.32749/nucleodoconhecimento.com.br/tecnologia/radiofrequencia-em-bibliotecas

\section{RESUMO}

O objetivo deste artigo é analisar se os pontos positivos e negativos apontados em artigos a respeito do uso da identificação por radiofrequência em bibliotecas, correspondem à realidade na prática, analisando a percepção dos funcionários de bibliotecas no Brasil, que já fazem uso desta tecnologia. Este artigo compila algumas bibliotecas em vários estados do Brasil que já fazem uso desta tecnologia, e busca, através de um questionário formulado utilizando a escala Likert, com 18 perguntas fechadas de 1 (discordo totalmente) a 5 (concordo totalmente) e uma pergunta aberta, analisar a percepção dos funcionários a respeito dos pontos positivos e negativos do uso da identificação por radiofrequência no dia a dia do funcionamento do setor. O referido questionário foi construído utilizando-se da ferramenta Google

\footnotetext{
${ }^{1}$ Mestrado (concluindo), Pós-graduação lato sensu em Economia e Tecnólogo em Sistemas de Computação.

${ }^{2}$ Orientador. Doutorado em Engenharia Civil. Mestrado em Engenharia Civil. Especialização em Engenharia de Segurança do Trabalho. Graduação em Arquitetura e Urbanismo.
}

RC: 94806

Disponível em:

https://www.nucleodoconhecimento.com.br/tecnologia/radiofrequencia-em- 
Forms e enviado via e-mail para as bibliotecas apontadas neste estudo. Por fim conclui-se que, com relação aos pontos negativos, o alto custo de implantação da tecnologia e possíveis problemas de interferência no uso das ferramentas são verificados na prática, concordando com os autores que apontaram. Possíveis problemas de software também foram verificados em algumas bibliotecas. Os outros pontos negativos não encontraram respaldo no questionário. Com relação aos pontos positivos, com exceção de uma menor demanda de funcionários no setor e uma diminuição de problemas por lesão, os outros benefícios apontados no uso da tecnologia de identificação por radiofrequência foram verificados nas bibliotecas pesquisadas. Este artigo tem como foco servir de base para um processo decisório de gestores que buscam atualizar a tecnologia em seus setores de biblioteca, podendo pesar os pontos positivos e negativos da implantação desta tecnologia.

Palavras-chave: RFID, radiofrequência, biblioteca.

\section{INTRODUÇÃO}

A tecnologia de RFID (Identificação por Radiofrequência) é uma das que mais tem se destacado no uso em bibliotecas, permitindo maior automação e segurança, facilitando o controle do acervo da biblioteca, facilitando o gerenciamento de informações e permitindo uma maior autonomia para os usuários do setor (SILVEIRA; VALMORBIDA, 2016). Isso permite que as bibliotecas possam se modernizar e prestar um melhor serviço aos seus usuários, e facilitar o trabalho de seus funcionários.

Uma etiqueta (ou tag), um leitor/escritos de tags e uma antena são os componentes mais básicos da tecnologia de RFID. A etiqueta é composta de um chip principal, juntamente com outros circuitos, e possui um código de identificação única e é capaz de armazenar informações. O leitor/escritor é a ferramenta capaz de ler e escrever dados nas tags, podendo este ser fixo ou um leitor portátil de mão. E a antena é a responsável por fazer a transmissão, através de ondas eletromagnéticas, 
das informações entre as tags e os leitores. A tecnologia de RFID já é utilizada em bibliotecas e em diversos setores há mais de 20 anos (ZHOU, 2019).

O uso desta tecnologia em bibliotecas consiste na identificação dos itens do acervo, como livros, revistas, bens de mídia, através das etiquetas de RFID, utilização de balcões de auto empréstimo e auto devolução, que oferece um self service aos usuários, que podem pegar e devolver os itens sem precisar passar por um funcionário, portais antifurtos, controle de inventário entre outros. O sistema mais utilizado em bibliotecas é o de código de barras, e a RFID vem para superar as dificuldades desse sistema (MADDILETI et al, 2020). Os benefícios propostos pela adoção desta tecnologia consistem em uma economia de custo e tempo no processamento dos bens do setor, uma melhoria nos serviços prestados aos clientes da biblioteca, diminuição de roubos e furtos de livros, diminuição do trabalho manual, entre outros benefícios (MOHAMMED et al., 2019).

Este artigo tem como objetivo identificar a percepção de relevância dos pontos positivos e negativos do uso da RFID nas bibliotecas brasileiras que já fazem uso desta tecnologia. Para isso foi criado um questionário que busca avaliar, através dos funcionários, a percepção desses atributos levantados por diversos autores, a respeito dessa tecnologia. Desta forma, este artigo visa a servir como uma base para um processo decisório do gestor que estiver planejando atualizar o sistema de gestão de seu setor de biblioteca, uma vez que ele pode avaliar os aspectos positivos e negativos deste sistema que foram experimentados na prática em outras bibliotecas.

\section{ASPECTOS TEÓRICOS DO ESTUDO}

As bibliotecas mais modernas têm se adequado e utilizado novas tecnologias para modernizar e automatizar suas funções por meio da RFID, como descrito previamente (RAHMAN; ISLAM, 2019; NISHA, 2018). As bibliotecas são um local adequado para o desenvolvimento rápido desta tecnologia, uma vez que ela permite 
automatizar diversas funções executadas nos processos de gestão de uma biblioteca, evitando lesões por esforço repetitivo e poupando os funcionários, permitindo rápido auto empréstimo aos usuários e melhorando a eficácia dos inventários (NOUDOOSTBENI; KAUR; JENATABADI, 2018). Esta tecnologia tem sido utilizada por bibliotecas no Brasil e no mundo todo para facilitar seus processos e melhorar sua eficácia.

Em Bangladesh, apesar de a adoção da RFID ainda não ter alcançado um número satisfatório, a quantidade de bibliotecas que usam esta tecnologia para automação vem aumentando todo ano. No momento, nove bibliotecas universitárias fazem uso desta tecnologia (RAHMAN; ISLAM, 2019). Sunil e Ojha (2018) citam algumas bibliotecas famosas na Índia que usam a tecnologia de RFID, como o Instituto Indiano de Ciência, em Bangalore, a biblioteca do Parlamento e a universidade Indiana de Direito, em Délhi, entre muitas outras. Ainda na Índia, cinco em cada dez bibliotecas dos Institutos de Tecnologia Indianos usam a tecnologia de RFID. Há muitos casos na Índia, como na biblioteca da Universidade de Pune Jayakar, houve problemas iniciais por conta da falta de treinamento dos funcionários no uso desta tecnologia. Porém, este problema foi minimizado com cursos para os funcionários, e a tecnologia se provou útil. (BANSODE; DESALE, 2009). Observa-se em artigos diferentes casos de sucesso, como na Inglaterra e na Índia, apesar do custo de implantação ainda ser alto em alguns locais.

Em Délhi, nas bibliotecas de Defesa Científica, do Instituto de Leis Indiano e do Centro Nacional de Documentação de Ciência Social, observou-se que esta tecnologia é uma possível solução para os problemas enfrentados, e que é certo que o futuro das bibliotecas está no uso desta tecnologia, entretanto o custo de implantação ainda é um fator a ser considerado, tornando-se proibitivo para pequenas bibliotecas (NISHA, 2018). Apesar disso, entende-se que, apesar do seu alto custo, a adoção em massa com o tempo fará os custos de implementação caírem (MADHUSUDHAN, 2010). 
Em Singapura, de acordo com o Conselho Nacional de Biblioteca, a maioria das bibliotecas usam a tecnologia RFID, resultando em nove milhões de livros e DVDs utilizando as etiquetas antifurto e com capacidade para auto empréstimo. $\mathrm{Na}$ Austrália, as bibliotecas do Conselho da Cidade de Brisbane usam RFID desde 2001. Na biblioteca da Universidade de Tecnologia de Sydney se concluiu que a aplicação da RFID de maneira inovadora melhora a eficiência dos processos e da gestão dos itens do acervo, bem como melhora a experiência do usuário (CHELLIAH; SOOD; SCHOLFIELD, 2015). Além desses dois casos, registra-se implantações bem-sucedidas nos Estados Unidos, Reino Unido, Canadá, Coréia do Sul e Nova Zelândia (YUSOF; SAMAN, 2016). No Japão, na biblioteca da Universidade Kyushu, também foi implementado um sistema de gerenciamento por RFID (FUJISAKI, 2015).

No Reino Unido, a primeira implantação da RFID em bibliotecas para controlar a movimentação do acervo e prover segurança foi na biblioteca Millennium em Norfolk e Norwich, em 2001. Desde então, a RFID foi instalada na biblioteca da universidade de Oxford, de Nottingham Trent e na biblioteca pública de Colchester, bem como na biblioteca da universidade de Middlesex (HOPKINSON, CHANDRAKAR, 2006).

Na Rússia, esta tecnologia já deixou de ser surpresa nas bibliotecas, e a expansão da utilização deste sistema tem se desenvolvido nos últimos anos, tendo o projeto inicial sido implantado em 2006 na biblioteca pública russa de Técnicas Científicas, mas a primeira biblioteca que funcionou completamente com este sistema implantado em 2008, foi a biblioteca da Universidade Estatal de St. Petersburgo (TIMOSHENKO, 2016).

No Brasil, a partir do início dos anos 2000, algumas bibliotecas começaram a adotar a RFID, como a Pontifícia Universidade Católica do Rio Grande do Sul (PUCRS), pioneira no uso de equipamentos de auto empréstimo. A instalação na PUCRS foi a maior instalação de equipamentos de RFID da América Latina (VIANA, 2016). No Centro Universitário Univates, Rio Grande do Sul, o setor de biblioteca implantou 
esta nova tecnologia, etiquetando cerca de 130 mil itens durante dois meses e vinte dias. O processo de preparação do acervo para receber esta tecnologia foi demorado e custoso, mas com um planejamento adequado e uma ajuda de recursos de tecnologia da informação que possibilite gerenciar todo o processo, houve maior agilidade e confiabilidade (SILVEIRA; VALMORBIDA, 2016).

Em 2011, a biblioteca do campus João Dias da Silveira, da UNESP, em Rio Claro, começou a implantar a RFID e a possibilitar os serviços de auto empréstimo e auto devolução. O serviço foi bem aceito entre os usuários da biblioteca e os problemas encontradas foram considerados pontuais, podendo ser solucionados com a convivência dos usuários com a tecnologia (PUERTA et al., 2013). Já na biblioteca Pedro Aleixo, da Câmara dos Deputados, o processo de implantação do RFID terminou no meio do ano de 2013, originário de um processo de licitação conjunto com a biblioteca Ministro Oscar Saraiva, do Superior Tribunal de Justiça (STJ), onde também é utilizado a RFID atualmente. Após uma avaliação com alguns usuários da biblioteca Pedro Aleixo, concluiu-se que o uso da solução tecnológica RFID é, muitas das vezes, uma das melhores soluções para melhorar os serviços do setor. (SANTOS, 2013)

A Biblioteca Pública da cidade de São Paulo (BSP) e a biblioteca da Universidade Federal de Uberlândia (UFU) também contam com esta tecnologia. Em entrevista, um bibliotecário Sênior da BSP cita como benefícios desta tecnologia a facilidade nos empréstimos e no inventário. Com relação às limitações, o entrevistado afirma que a tecnologia não funciona bem em livros que contenham metal na capa, que o material tem custo elevado e que a etiqueta é grande e visível, o que pode facilitar sua retirada caso haja intenção de furto. Já na biblioteca da UFU, o entrevistado, um bibliotecário-documentalista, afirma que como benefícios a RFID torna mais ágil o processo de registro, empréstimo e realização do inventário, o que torna o atendimento mais rápido e satisfatório para funcionários e clientes. $E$ com relação às limitações, o entrevistado não citou nenhuma. (RIBEIRO; SOUZA, 2017). 


\section{METODOLOGIA}

\subsection{CLASSIFICAÇÃO DA PESQUISA}

Segundo Creswell (2009), a pesquisa qualitativa é um meio que se pode usar para explorar e entender o sentido que indivíduos ou grupos atribuem a um determinado problema social ou humano. Miguel et al. (2011) afirmam que a principal preocupação da pesquisa qualitativa é obter informações sobre a perspectiva dos indivíduos, e como entender o ambiente onde a problemática acontece. Sendo assim, o ambiente natural dos indivíduos é o ambiente da pesquisa. Portanto, este trabalho usará uma abordagem qualitativa de pesquisa, com o intuito de avaliar a percepção dos pesquisados sobre os desafios que enfrentam no seu ambiente de trabalho com relação à tecnologia que usam para fazer a gestão do setor onde estão inseridos. O objetivo é traçar um paralelo com os pontos levantados na literatura, para se extrair conclusões a respeito de se o uso de nova tecnologia melhora o funcionamento do ambiente de trabalho.

Pesquisa pode ser descrita como um esforço sistemático e organizado para investigar um problema específico que precisa de solução. Nesse contexto, a pesquisa organizacional costuma estar relacionada com a proposição de soluções para problemas reais. Quando a pesquisa possui foco e ênfase em atingir resultados mensuráveis específicos a determinada organização, pode-se caracterizá-la como pesquisa aplicada (GRAY, 2009). Este trabalho possui natureza de pesquisa aplicada, uma vez que atende às características definidas por Gray (2009), que são: melhorar o entendimento de problemas organizacionais específicos; criar soluções para problemas organizacionais; desenvolver conclusões de relevância prática aos stakeholders. Também tem como fundamentos a necessidade de gerar conhecimentos para uma aplicação prática, dirigidos às soluções de problemas específicos (GIL, 2002). Ainda conforme Moresi (2003), a pesquisa aplicada é aquela cujo objetivo é gerar conhecimentos para aplicação prática dirigidos à solução de problemas específicos.

RC: 94806

Disponível em:

https://www.nucleodoconhecimento.com.br/tecnologia/radiofrequencia-em- 
O estudo proposto é classificado, quanto aos seus objetivos, como uma pesquisa exploratória, dado que se destina a obter maior familiaridade com o problema e aprimorar ideias. Gil (2002) identifica que, na maioria dos casos, pesquisas deste tipo envolvem o levantamento bibliográfico, abordagens com pessoas que tiveram experiências práticas com o problema pesquisado e a análise de exemplos que estimulem a compreensão. Nesse sentido este estudo envolve investigações junto a amostra da população envolvidas com pesquisas cientificas no cenário nacional por meio de técnicas de levantamento e tratamento qualitativos e quantitativos de dados através do uso de questionários

Creswell (2009) afirma que o estudo de caso é uma estratégia de investigação onde o pesquisador explora com profundidade um programa, evento, atividade, processo ou um ou mais indivíduos. De acordo com Moresi (2003), o estudo de caso é circunscrito a uma ou poucas unidades, como pessoa, família, órgão público entre outras. Portanto, esse estudo se caracteriza com relação aos seus procedimentos como um estudo de caso, pois faz um estudo dos processos que compõem um setor de biblioteca que faz uso da tecnologia de RFID, a fim de levantar os impactos do uso dessa tecnologia no dia a dia do setor.

\subsection{UNIVERSO E AMOSTRA}

A pesquisa de campo teve como amostra bibliotecas que já vivem a experiência de utilização da tecnologia RFID na gestão de seu acervo. Para essa pesquisa a amostra foi composta de bibliotecas brasileiras por conveniência. Buscas pela internet foram feitas para levantar informações de quais bibliotecas já usam essa tecnologia, bem como também foram utilizados artigos encontrados que descrevem bibliotecas que adotaram a RFID. Uma vez compilada essas informações, foram enviados e-mails para essas bibliotecas, estes que foram encontrados nos sites, convidando os funcionários a participarem da pesquisa. Após a obtenção da resposta positiva, de que participariam da pesquisa, foi enviado o link com o questionário hospedado no Google Forms. Foi solicitado que os respondentes 
fossem funcionários do setor, tanto bibliotecários quanto funcionários do setor que fizessem 0 atendimento ou executassem outras funções, como catálogo, etiquetagem, que usassem a RFID diretamente, independentemente de sua formação acadêmica, dando preferência à funcionários que já tivessem domínio da tecnologia. O Quadro 1 mostra quais as bibliotecas aceitaram participar da pesquisa.

Quadro 1: Reúne as bibliotecas que aceitaram participar do estudo, respondendo ao questionário, e uma descrição destas encontradas em seus respectivos sites.

\section{BIBLIOTECA}

Biblioteca

Senado Federal

\section{LOCALIZAÇÃO/DESCRIÇÃO}

do Localizada no Distrito Federal, Goiás. Foi criada em 18 de Maio de 1826 e hoje dispõe de um acervo multidisciplinar, especializado em Ciências Sociais, com obras da área de Direito, Ciência Política, Economia, Sociologia, Antropologia e Educação. Conta também com um acervo de aproximadamente 215 mil livros, mais de 336 mil fascículos e cerca de 2.517 itens como CDs, DVDs, mapas e slides. (SENADO, 2020).

\section{Biblioteca Central Localizada em Uberlândia, Minas Gerais.}

Santa Mônica da

\section{Universidade}

Federal de

\section{Uberlândia (UFU)}

Biblioteca Ministro Localizada no Distrito Federal, Brasília. É especializada na Oscar Saraiva, área jurídica e tem como missão oferecer informação em Superior Tribunal doutrina e legislação necessárias ao apoio das atividades de Justiça (STJ) judicantes e administrativas do Tribunal. Seu acervo abrange todas as áreas do Direito, com destaque especial para o Direito Civil e Processual Civil, Penal e Processual Penal. Possui um acervo de cerca de 170 mil documentos 
em formato impresso. Além do acervo físico, possui mais de 100 mil documentos jurídicos em formato digital. (STJ, 2020).

Biblioteca da Localizada em Lajeado, Rio Grande do Sul.

Universidade do

Vale do Taquari

(UNIVATES)

Biblioteca do Localizada em Nova Hamburgo, Rio Grande do Sul. Sua

Campus II - Paulo função é ser um espaço multiuso, de convivência, que oferta

Sérgio Gusmão, da um ambiente aconchegante, interativo e de aprendizado, Universidade

Feevale estimulando a construção do conhecimento, e não uma depositária de acervo e local de estudo tradicional. Adota atualmente a tecnologia de RFID, que permite automação e agilidade nos serviços, proporcionando aos acadêmicos uma maior autonomia através de auto empréstimos e auto devolução de livros, sem a necessidade de intermediação de atendimento físico no balcão. (UNIVERSIDADE FEEVALE, 2020).

Biblioteca

Universidade

Federal de Lavras (UFLA) da Localizada em Lavras, Minas Gerais. A Biblioteca Universitária teve seu início em 1958, segundo arquivos e informações pessoais, porém não existe qualquer documento oficial de criação e/ou inauguração. Em 2012 iniciou a implantação da RFID, a partir da constatação da necessidade de garantir a proteção do acervo e a possibilidade de otimização dos serviços prestados pela Biblioteca. O objetivo desta implantação era revitalizar a segurança e a gestão do acervo e aperfeiçoar o serviço de empréstimo, consequentemente melhorando a qualidade do atendimento. Conta com um total de 42.132 usuários registrados. (UFLA, 2020) 
Biblioteca

Universidade

Unisinos da Localizada em Porto Alegre, Rio Grande do Sul. Com um acervo somado todos os campi formados por cerca de 836 mil itens e uma área total de 227,38 metros quadrados, a biblioteca dispõe para a comunidade acadêmica a bibliografia dos cursos ofertados no campus, espaço para estudos individual e em grupo e os equipamentos de autoatendimento de RFID para alunos, professores e funcionários realizarem seus empréstimos e devoluções de forma autônoma. (UNISINOS, 2020)

do Localizada em Guarulhos, São Paulo.

\section{Campus Garulhos}

do Instituto Federal

de São Paulo (IFSP)

Biblioteca do

Campus Santa Inês do Instituto Federal do

Maranhão

(IFMA),

\section{Biblioteca}

do

Campus de Bauru da Universidade

Estadual Paulista (UNESP)
Localizada em Santa Inês, Maranhão. A biblioteca atende aos professores, alunos, servidores técnicos-administrativos do Instituto Federal do Maranhão e à comunidade local. Conta com um acervo de 2.285 títulos de livros e 10.557 exemplares. (IFMA, 2020)

Localizada em Bauru, São Paulo. A biblioteca iniciou seu atendimento em 1967, apesar do registro no Instituto Nacional do Livro ter ocorrido após 10 anos. Ocupa uma área de 1.466 metros quadrados, distribuídos entre acervo e área administrativa, e tem como missão disponibilizar informação em diversas mídias, oferecendo suportes às atividades de ensino, pesquisa e extensão da comunidade acadêmica, dessa forma colaborando com a geração de conhecimento para o desenvolvimento da universidade $\mathrm{e}$ qualidade de vida do cidadão.(UNESP, 2020)

Bibliotecas dos Localizados em várias cidades do Amazonas. 
campi

da

\section{Universidade}

Federal Rural da

Amazônia (UFRA)

Fonte: Elaboração própria (2020)

\subsection{INTRUMENTO DE COLETA DE DADOS}

Para coletar os dados desta pesquisa, foi utilizado um questionário gerado pela ferramenta Google Forms. O questionário era composto de 18 perguntas fechadas, com respostas na escala Likert, variando de 1 (discordo totalmente) a 5 (concordo totalmente), e no fim do questionário também havia uma pergunta aberta, permitindo ao respondente contribuir com mais informações que pudessem não ter sido contempladas nas perguntas fechadas. O questionário foi enviado por e-mail, durante o mês de Julho de 2020, para bibliotecas pelo Brasil que já fazem uso da tecnologia de RFID, a fim de avaliar o funcionamento desta tecnologia na prática, verificando se os pontos positivos e negativos levantados pela pesquisa bibliográfica são observados no dia a dia.

O Quadro 2 relaciona as perguntas elaboradas para o questionário com os respectivos pontos positivos e negativos. (LIMA, 2021):

Quadro 2: Relaciona cada pergunta do questionário enviado com o atributo positivo ou negativo atribuído ao uso da radiofrequência em bibliotecas.

\begin{tabular}{|l|l|l|}
\hline $\begin{array}{l}\text { No } \\
\text { Pergunta }\end{array}$ & Atributo & Pergunta \\
\hline $\mathbf{1}$ & Alto Custo & $\begin{array}{l}\text { O custo para implementação do RFID foi } \\
\text { alto ou foi de alguma forma impeditivo para } \\
\text { sua adoção. }\end{array}$ \\
\hline $\mathbf{2}$ & Interferência, & $\begin{array}{l}\text { Problemas } \\
\text { Problemas de leitura ou interferência }\end{array}$ \\
\hline
\end{tabular}

RC: 94806

Disponível em:

https://www.nucleodoconhecimento.com.br/tecnologia/radiofrequencia-em- 


\begin{tabular}{|c|c|c|}
\hline & $\begin{array}{l}\text { de Leitura e Problemas de } \\
\text { Performance }\end{array}$ & prejudicam a performance do sistema. \\
\hline 3 & Privacidade dos Usuários & $\begin{array}{l}\text { A falta de privacidade dos usuários } \\
\text { prejudica de alguma forma o sistema. }\end{array}$ \\
\hline 4 & $\begin{array}{l}\text { Possibilidade de } \\
\text { Interceptação de Dados e } \\
\text { Segurança }\end{array}$ & $\begin{array}{l}\text { Casos de interceptação dos dados ou } \\
\text { problemas com segurança prejudicam o } \\
\text { funcionamento do sistema. }\end{array}$ \\
\hline 5 & $\begin{array}{l}\text { Falta de Treinamento dos } \\
\text { Funcionários }\end{array}$ & $\begin{array}{l}\text { O treinamento dos funcionários para utilizar } \\
\text { o RFID foi demorado ou de alguma forma } \\
\text { difícil, tornando-se um obstáculo para o } \\
\text { uso do sistema. }\end{array}$ \\
\hline 6 & $\begin{array}{l}\text { Resistência dos Usuários } \\
\text { à Nova Tecnologia }\end{array}$ & $\begin{array}{l}\text { Houve resistência dos usuários às novas } \\
\text { tecnologias, como os balcões de } \\
\text { autoempréstimo ou autodevolução. }\end{array}$ \\
\hline 7 & Problemas de Software & $\begin{array}{l}\text { Problemas com o software do RFID } \\
\text { prejudicam o bom funcionamento do setor. }\end{array}$ \\
\hline 8 & $\begin{array}{l}\text { Problemas de Saúde } \\
\text { devido à Exposição a } \\
\text { Radiação Eletromagnética }\end{array}$ & $\begin{array}{l}\text { A exposição à radiação eletromagnética } \\
\text { proveniente do RFID trouxe algum relato } \\
\text { de problemas à saúde dos funcionários do } \\
\text { setor. }\end{array}$ \\
\hline 9 & $\begin{array}{l}\text { Ausência de Padrão } \\
\text { Internacional }\end{array}$ & $\begin{array}{l}\text { A ausência de padrão das etiquetas foi um } \\
\text { obstáculo para a adoção ou funcionamento } \\
\text { do sistema. }\end{array}$ \\
\hline 10 & $\begin{array}{l}\text { Permite Auto empréstimo } \\
\text { e Auto devolução pelos } \\
\text { Usuários }\end{array}$ & $\begin{array}{l}\text { O auto empréstimo e auto devolução dos } \\
\text { itens do acervo trouxe benefícios para o } \\
\text { setor, como redução da carga de trabalho, } \\
\text { diminuição de filas, entre outros. }\end{array}$ \\
\hline 11 & $\begin{array}{l}\text { Reduz o Esforço dos } \\
\text { Funcionários e Melhora } \\
\text { Eficiência }\end{array}$ & $\begin{array}{l}\text { Houve redução na carga total de trabalho e } \\
\text { aumento da eficiência dos funcionários por } \\
\text { conta da adoção do RFID. }\end{array}$ \\
\hline
\end{tabular}

RC: 94806

Disponível em:

.


12

Previne Furtos do Acervo Houve diminuição dos furtos dos itens do acervo após a adoção desta nova tecnologia.

$13 \quad$ Facilita o Inventário O inventário do acervo é feito de forma mais rápida e fácil com o RFID.

14 Permite Múltipla Leitura O RFID permite que múltiplos itens sejam de Itens lidos ao mesmo tempo.

15 Necessidade de Menos Há uma necessidade de menos Funcionários no Setor funcionários no setor atualmente por conta desta tecnologia.

$16 \quad$ Reduz Erro Humano Houve redução no erro humano por conta da automatização dos processos.

17

Reduz Lesões por Esforço Houve redução nos casos de lesão por Repetitivo esforço repetitivo após a adoção desta nova tecnologia.

18

Alta Durabilidade e Baixo As etiquetas, leitores e outros itens de Custo de Manutenção hardware são duráveis e impõem uma menor carga de trabalho para manutenção.

Fonte: Elaboração própria (2020)

\subsection{TRATAMENTO DE DADOS}

Para analisar os dados que foram coletados na pesquisa de campo, foi utilizado o método de análise de conteúdo para as perguntas abertas. A análise de conteúdo pode ser definida, enquanto método, como um conjunto de técnicas de análise das comunicações, que faz uso de procedimentos sistemáticos e objetivos com o objetivo de descrever o conteúdo das mensagens (BARDIN, 2009).

Pode-se afirmar que o método de análise de conteúdo é uma das abordagens mais comuns utilizadas para análise de dados qualitativos, que essencialmente trata de 
fazer inferências acerca dos dados coletados, com o intuito de identificar, de forma sistemática e objetiva, características específicas dos dados coletados (GRAY, 2009).

\section{RESULTADOS E DISCUSSÃO}

O questionário foi enviado para as bibliotecas apresentadas no Quadro 1. Apenas funcionários do setor que trabalhassem na gestão do acervo ou atendimento ao público e que tivessem contato direto com a tecnologia da RFID responderam ao questionário. Um total de 26 respostas. As respostas obtidas são apresentadas no Gráfico 1.

Gráfico 1: Apresenta as respostas do questionário em uma forma visual através de gráfico em barras, para facilitar o entendimento através da fácil visualização.

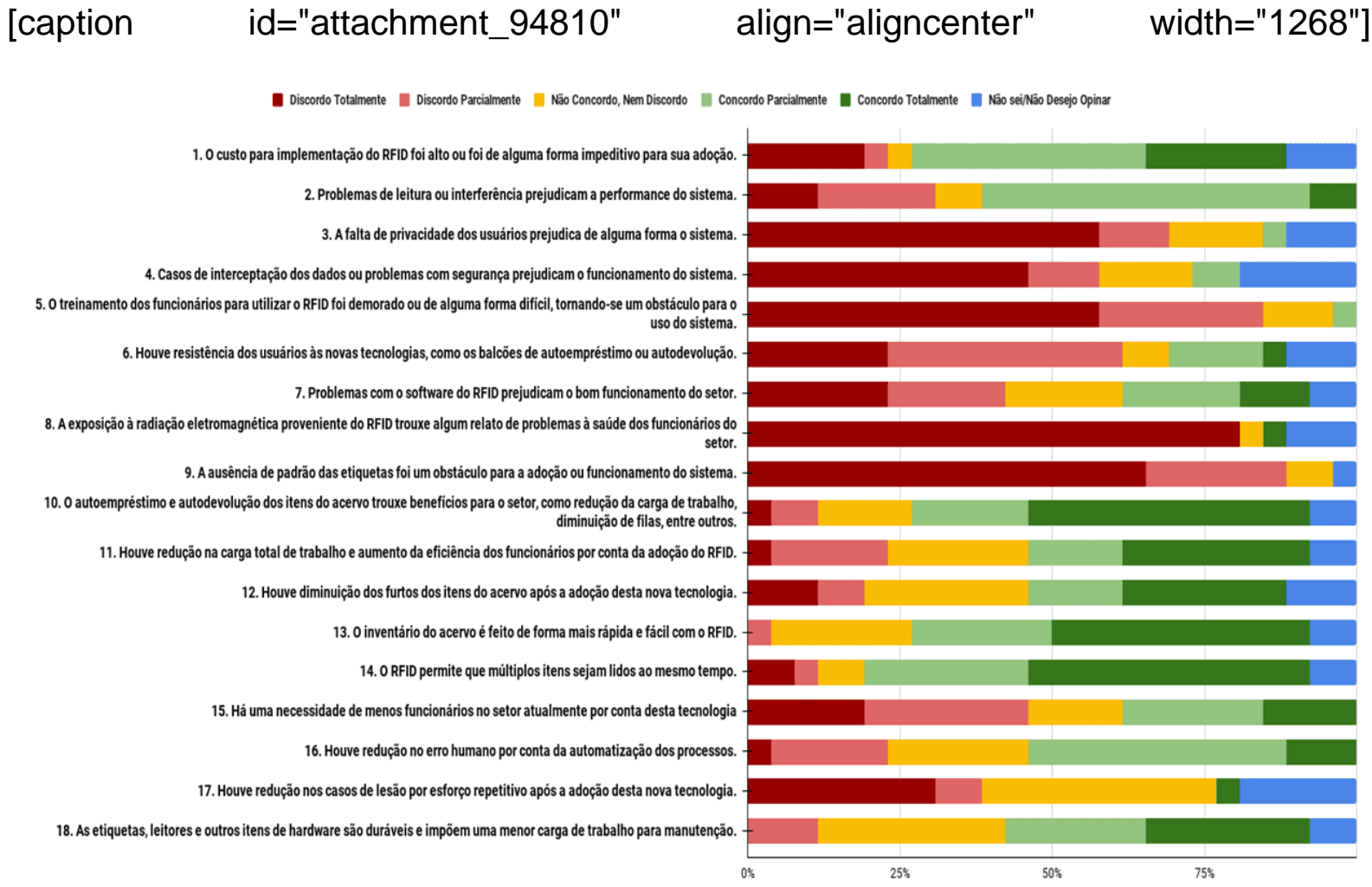

Fonte: Elaboração própria (2020).

RC: 94806

Disponível em:

https://www.nucleodoconhecimento.com.br/tecnologia/radiofrequencia-em-

$\underline{\text { bibliotecas }}$ 


\subsection{ATRIBUTOS NEGATIVOS}

Conforme é possível ver no gráfico 1, a Pergunta 1, que visava a avaliar se os custos de implantação da estrutura do RFID foi um obstáculo para a adoção dessa tecnologia, a percepção dos respondentes foi majoritariamente de acordo com esta afirmação, o que está em consonância com os autores citados nesse trabalho. Apesar de ser uma tecnologia que já vem sendo adotada pelo mundo nos mais diversos setores, os custos para sua implantação podem vir a ser proibitivos para bibliotecas de pequeno porte ou que possuem pouca circulação de pessoas. Conforme declarou um dos respondentes do questionário, na pergunta aberta localizada no final do questionário: "Outro ponto a ser questionado é o seu elevado custo. Como o sistema depende de outros periféricos como câmeras de segurança, no todo, o seu preço sairá bastante caro para ser completo."

Ainda que os custos sejam elevados, outro respondente afirmou: "Em geral, é um superinvestimento, caro, mas que facilita muito os processos internos da biblioteca e direciona o atendimento para outras necessidades do usuário. Espero ter ajudado com essas colocações."

A tendência esperada é que com a adoção gradual, esta tecnologia possa ter seus custos mais atrativos, conforme acontece com diversas tecnologias.

Também é possível ver que a Pergunta 2, que visava a avaliar se a performance do sistema sofre algum impacto negativo devido a problemas de leitura ou interferência, teve respostas que em sua maioria concordavam com os autores que levantaram estes fatos. Um dos respondentes declarou que: "Apesar de facilitar muito o dia a dia dentro de uma biblioteca, o sistema por vezes é falho, precisa ter um analista em TI específico dentro da biblioteca para eventuais problemas, tanto de manutenção quanto treinamento. “

Outro respondente também acrescentou que:

RC: 94806

Disponível em:

https://www.nucleodoconhecimento.com.br/tecnologia/radiofrequencia-em- 
A leitura de múltiplos itens gera um resultado diferente do esperado no inventário. Algumas etiquetas não são lidas, cerca de $1 \%$ do acervo, considerando que não pode haver falhas o número é significativo (nós contamos a quantidade de livros na prateleira e lemos a mesma quantidade. Reparamos que ele lê estantes acima, abaixo e atrás, mesmo variando a calibragem).

Por sua vez, nas Pergunta 3 e 4, os respondentes discordaram majoritariamente que a falta de privacidade dos usuários e a interceptação de dados constituem um problema encontrado no uso do sistema de RFID. Nos sistemas que são baseados em códigos de barras, o histórico de empréstimo dos usuários também fica registrado no sistema, porém sem a possibilidade de auto empréstimo e auto devolução, os usuários necessariamente precisam passar pelo balcão de empréstimo onde um funcionário cadastrará no sistema os itens que estão sendo pegos. Já no sistema de RFID com balcões de auto empréstimo, isso não é necessário, então é de se esperar que haja na verdade uma privacidade maior, uma vez que os usuários não mais precisam mostrar o que estão alugando ao funcionário no balcão. E como não houve problemas de interceptação de dados nas bibliotecas que responderam ao questionário, percebe-se que os dados privados dos usuários também não sofrem problemas. De acordo com um respondente: "O RFID é seguro. A empresa que presta o serviço o faz com excelência. A integração com o software de gerenciamento da Biblioteca (Aleph) foi trabalhosa, mas com ótimos resultados."

$\mathrm{Na}$ Pergunta 5, que visava a avaliar se há alguma dificuldade no uso do sistema do ponto de vista dos funcionários, conforme apontou a literatura. É possível ver que as respostas dos funcionários que participaram da pesquisa discordam em maioria de que há alguma dificuldade e esta possivelmente atrapalharia o bom andamento do setor. É possível inferir que os sistemas que são utilizados nestas bibliotecas são facilmente dominados pelos trabalhadores.

Por sua vez, a Pergunta 6 tem como intenção verificar se houve alguma resistência, por parte dos usuários e frequentadores das bibliotecas, com relação às novas tecnologias que o RFID proporciona, como os balcões de auto empréstimo. As respostas em sua maioria foram de encontro ao apontado na literatura, mostrando 
que nestas bibliotecas consultadas, não houve, de forma geral, resistência com relação aos usuários. Porém um dos respondentes afirmou: "Fora a questão de resistência do usuário em utilizar a tecnologia. Ainda precisamos ter um funcionário por perto para auxiliar e indicar o uso. “

Nota-se que é possível que em alguns locais haja alguma resistência dos usuários à utilizar as novas ferramentas tecnológicas. Porém, como foram as respostas que vão ao encontro da afirmação feita na pergunta, pode-se supor que esses casos são raros e talvez possam deixar de ser um problema conforme o usuário vá aprendendo a mexer.

Podemos ver que a Pergunta 7 apresentou resultados equilibrados. Esta pergunta tem como objetivo avaliar se problemas com os softwares do RFID prejudicam o bom funcionamento do setor. Houve respondentes que concordaram e discordaram de maneira equilibrada. Um respondente afirmou: "Apesar de facilitar muito o dia a dia dentro de uma biblioteca, o sistema por vezes é falho, precisa ter um analista em TI específico dentro da biblioteca para eventuais problemas, tanto de manutenção quanto treinamento. “

Outro respondente afirmou: "a integração com demais sistemas deve ser bem-vista, pois influencia em tudo."

As Perguntas 8 e 9 apontaram uma discordância majoritária com os possíveis atributos negativos apontados na literatura. Estas buscavam avaliar, respectivamente, se houve algum relato de problemas de saúde derivados da radiação eletromagnética utilizada pelo RFID e se a ausência de padrões das etiquetas dificultou de alguma forma a adoção ou uso do sistema. Ambas mostraram que estes problemas levantados por alguns autores como possíveis impactos negativos não foram detectados de forma relevante no dia a dia das bibliotecas pesquisadas. 
Estes atributos negativos foram levantados através de uma análise de diversos artigos de outros pesquisadores que avaliaram o uso desta tecnologia em setores de biblioteca (LIMA, 2021).

\title{
4.2 ATRIBUTOS POSITIVOS
}

A Pergunta 10 tem como objetivo avaliar se os balcões de auto empréstimo e auto devolução, que permitem ao usuário fazer um autoatendimento na hora de alugar ou devolver os itens locados, trouxeram benefícios para o setor, conforme aponta a literatura. As respostas concordam em sua maioria que houve benefícios, de acordo com o que é afirmado pelos autores citados neste trabalho.

A Pergunta 11, por sua vez, buscava medir se houve redução na carga total de trabalho e aumento da eficiência por conta das facilidades que a tecnologia de RFID provê, como a diminuição dos atendimentos de balcão, maior facilidade e rapidez de inventário entre outras, conforme afirma a literatura. Houve uma concordância dos pesquisados com o que é afirmado pelos autores, a percepção de que houve esta redução e melhoria da eficiência no setor. Embora em uma das bibliotecas pesquisadas o RFID ainda não esteja operando com toda sua potencialidade, um dos respondentes compartilhou suas expectativas positivas:

\begin{abstract}
Nossa universidade passou a adotar recentemente o sistema e ainda não está usando o autoatendimento pois não foi entregue pela empresa devido a suspensão do trabalho devido a pandemia da COVID-19. O inventário também ainda não foi realizado, mas imaginamos que vai facilitar e diminuir o trabalho e o tempo de execução, assim como deve diminuir o trabalho do atendente quando autoatendimento estiver em funcionamento. O processo de registro doas materiais é muito simples e fácil de entender todos os atendentes e equipe de processamento conseguem fazer.
\end{abstract}

A Pergunta 12 buscava verificar se houve redução dos furtos de itens do acervo graças à segurança realizada através dos portais de segurança que ficam nas entradas e saídas da biblioteca. Embora as respostas apontem uma leve concordância, alguns respondentes informaram que ainda é possível encontrar problemas: "O sistema possui muitos pontos positivos, porém ainda precisa ser 
melhorado, principalmente no quesito segurança, já que, o mesmo pode ser burlado de alguma forma pelos usuários."

Outro respondente também apontou:

No caso do portal, livros colocados em bolsas ou colocados no interior de livros maiores não são detectados pela máquina, ocasionando furto. No caso da biblioteca da UFLA, mesmo com o portal, é necessário ter servidores revistando bolsas e mochilas na saída dos usuários.

Também foi apontado, por outro pesquisado: "A implantação RFID facilitou sim os processos, no entanto ela é muito visível para o usuário que a fita eletromagnética, portanto mais fácil de ser retirada caso haja intenção de furto."

Portanto, é notável que é um quesito que merece bastante atenção e planejamento na hora de implantação do RFID

Com a Pergunta 13 buscava-se avaliar se o processo de inventário, quando é necessário levantar todos os itens físicos presentes na biblioteca para comparar com as informações cadastradas no sistema, a fim de avaliar se há alguma inconsistência, as respostas foram majoritariamente positivas, concordando com os autores que afirmam que o RFID facilita este processo. Porém um dos respondentes apontou: "Em relação ao inventário, é preciso um auxílio maior na utilização do equipamento de leitura e acontece de alguns materiais não serem rastreados pelo aparelho. “

Da mesma forma, a Pergunta 14 buscava saber se a leitura múltipla de itens era possível com o RFID. Esse é um dos pontos que facilita o inventário, pois não é necessário ler o código dos itens individualmente, tarefa que torna o inventário com código de barras mais vagaroso. As respostas concordaram majoritariamente com a literatura, afirmando que essa é uma função do RFID. Porém um dos respondentes afirma: 
A leitura de múltiplos itens gera um resultado diferente do esperado no inventário. Algumas etiquetas não são lidas, cerca de $1 \%$ do acervo, considerando que não pode haver falhas o número é significativo (nós contamos a quantidade de livros na prateleira e lemos a mesma quantidade. Reparamos que ele lê estantes acima, abaixo e atrás, mesmo variando a calibragem)

Nota-se que mesmo trazendo uma facilidade, um desafio novo pode surgir.

Na Pergunta 15, que buscava saber se há uma necessidade menor de funcionários no setor graças ao uso do RFID, houve uma leve discordância com relação à literatura. A maioria dos pesquisados apontaram que discordam dessa observação. Uma das possibilidades para essa discordância podem ser os pontos apontados em outras perguntas, como a necessidade de servidores para ajudar os usuários no uso das novas tecnologias ou para aplicar as medidas de segurança. Possivelmente com a maturação desta tecnologia no setor, estes funcionários possam ser redirecionados para outras funções dentro do mesmo setor ou realocados para outros setores. Já na Pergunta 16, que avaliava se houve redução de erro humano com esta nova tecnologia, houve uma concordância majoritária, em linha com o que é apontado pela literatura.

Houve discordância também na Pergunta 17, que questionava se houve redução nos casos de lesão por esforço repetitivo. Importante notar que a taxa de respostas "Não sei/Não quero responder" e "Não concordo, nem discordo" foi alta, o que pode sinalizar que não houve casos reportados nestas bibliotecas pesquisadas, portanto não foi possível aos respondentes avaliar se houve alguma redução ou não. $E$ aos que responderam que não houve redução, é importante notar que ainda que traga alguns benefícios, o trabalho manual continua intenso, ou seja, ainda é necessário etiquetar todos os itens, usar teclado para navegar no sistema entre outras tarefas que continuam necessárias no setor.

Por fim, a Pergunta 18 esperava avaliar a durabilidade das etiquetas e outros itens que compõem o hardware do RFID. As respostas positivas estão em consonância com o apontado na literatura.

RC: 94806

Disponível em:

https://www.nucleodoconhecimento.com.br/tecnologia/radiofrequencia-em- 
Estes atributos positivos foram levantados através de uma análise de diversos artigos de outros pesquisadores que avaliaram o uso desta tecnologia em setores de biblioteca (LIMA, 2021).

\section{CONSIDERAÇÕES FINAIS}

A RIFD é uma tecnologia bastante versátil, podendo trazer inovações para os mais diversos setores, como logística, varejo, hospitalar, bibliotecário. Mesmo tendo sido desenvolvido há um tempo considerável, no Brasil ainda não é uma ferramenta tão difundida no setor de biblioteca. Alguns fatores podem ainda servir como obstáculos para uma adoção em larga escala, como por exemplo o alto custo.

Este trabalho teve como objetivo fazer um estudo de caso com bibliotecas espalhadas pelo Brasil que já fazem uso dessa tecnologia, a fim de confrontar os pontos positivos e negativos levantados na literatura, com o uso desta tecnologia no dia a dia por essas bibliotecas, com o intuito de verificar se estes atributos apontados pelos autores se confirmam na prática.

Conclui-se que os pontos negativos sobre o alto custo da tecnologia, possíveis problemas de leitura e interferência do sistema, descritos na literatura, foram corroborados com as respostas dos investigados com o uso de questionários, ou seja, na maioria das bibliotecas pesquisadas, houve concordância que estes são obstáculos ainda presentes. Outro ponto negativo que apresentou respostas com porcentagens parecidas de concordo e discordo foi o que afirma que problemas com o software podem atrapalhar o funcionamento da biblioteca. Os outros pontos negativos que foram apontados pelos autores citados neste trabalho não encontraram corroboração nas bibliotecas pesquisadas.

Com relação aos pontos positivos que foram levantados, a afirmação de que a adoção da RFID trouxe uma menor necessidade de funcionários no setor e diminuiu os casos de lesão por esforço repetitivo não encontraram respaldo nas respostas dos pesquisados. Possivelmente a adoção desta tecnologia trouxe novos desafios, o

RC: 94806

Disponível em:

https://www.nucleodoconhecimento.com.br/tecnologia/radiofrequencia-em- 
que manteve a necessidade do mesmo número de trabalhadores para lidar com essa nova realidade, como apontou um dos pesquisados, ao afirmar que, embora os balcões de auto empréstimo sejam úteis, ainda há a necessidade de um funcionário para auxiliar os usuários. Quanto as lesões por esforço repetitivo são possíveis que não haja uma diminuição significativa, pois os funcionários ainda necessitam usar ferramentas que podem proporcionar esse tipo de lesão, como mouse, teclado, e ainda mantém o trabalho manual de etiquetar os livros, guardá-los nas estantes, entre outras funções.

Nota-se, portanto, que a maioria dos pontos negativos não foi verificado no uso diário deste sistema nas bibliotecas pesquisadas, e que a maioria dos pontos positivos foi corroborada, o que favorece fortemente a tecnologia de RFID como uma alternativa mais moderna, eficaz e segura para os possíveis problemas encontrados em bibliotecas. Como a RFID possui outras aplicabilidades, é interessante avaliar se haveria impacto positivo na adoção desta tecnologia também em outros setores.

\section{REFERÊNCIAS}

BANSODE, Sadanand Y.; DESALE, Sanjay K. Implementation of RFID technology in University of Pune Library. Program, [s. I.], v. 43, n. 2, p.202-214, 2009. Disponível em: https://www.emeraldinsight.com/doi/abs/10.1108/00330330910954406. Acesso em: 7 fev. 2019.

BARDIN, L. Análise de Conteúdo. 5 ed. Lisboa, Portugal: Edições 70, 2009.

CHELLIAH, John; SOOD, Suresh; SCHOLFIELD, Sally. Realising the strategic value of RFID in academic libraries: a case study of the University of Technology Sydney. The Australian Library Journal, [s. I.], v. 64, n. 2, p. 113-127, 1 jan. 2015. Disponível em: https://opus.lib.uts.edu.au/handle/10453/37737. Acesso em: 12 fev. 2019.

CRESWELL, John W. Research Design: Qualitative, Quantitative and Mixed Methods Approaches. 3 ed. Estados Unidos da América: SAGE Publications, 2009.

RC: 94806

Disponível em:

https://www.nucleodoconhecimento.com.br/tecnologia/radiofrequencia-em-

bibliotecas 
FUJISAKI, Kiyotaka. An RFID-based System for Library Management and Its Performance Evaluation. In: Ninth international conference on complex, intelligent, and software intensive systems, 2015, Blumenau. Artigo [...]. IEEE, 2015. p. 105109. Disponível em: https://ieeexplore.ieee.org/document/7185173. Acesso em: 10 mar. 2019.

GIL, Antonio Carlos. Como elaborar projetos de pesquisa. 4 ed. São Paulo: Editora Atlas, 2002.

GRAY, David E. Pesquisa no mundo real. 2. ed. Porto Alegre, RS: Artmed, 2009.

HOPKINSON, Alan; CHANDRAKAR, Rajesh. Introducing RFID at Middlesex University Learning Resources. Program, [s. I.], v. 40, n. 1, p. 89-97, 2006. Disponível

em:

https://www.emeraldinsight.com/doi/abs/10.1108/00330330610646834. Acesso em: 19 fev. 2019.

IFMA. Biblioteca, 2020. Disponível em: <https://santaines.ifma.edu.br/biblioteca/>. Acesso em: 29/08/2020.

LIMA, Diego Andrade Velloso de. 3RD NIIC - NECSOS' INTERNATIONAL AND INTERINSTITUTIONAL COLLOQUIUM, 3., 2021, Congresso Online. Radiofrequencia (RFID) na gestão do acervo de bibliotecas: um estudo bibliométrico. 2021. 6-19.

Disponível em: https://8d8cfe1a6d174810856ed5f789ade035.filesusr.com/ugd/5cf811_080b3cca98e 04e7c81789baa7262857b.pdf. Acesso em: 12 jun. 2021.

MADDILETI, Telugu; KATKAM, Sathwik; KAMBLE, Nihal; RAMIREDDY, Srinivas Kalyan. Library Automation Using Microcontroller Based RFID Technology and Reinstating System. International Journal of Advanced Science and Technology, [s. I.], v. 29, n. 6, p. 2076-2085, 23 abr. 2020. Disponível em: http://sersc.org/journals/index.php/IJAST/article/view/13477. Acesso em: 22 jul. 2020

RC: 94806

Disponível em:

https://www.nucleodoconhecimento.com.br/tecnologia/radiofrequencia-em- 
MADHUSUDHAN, Margam. RFID technology implementation in two libraries in New Delhi. Program, [s. I.], v. 44, n. 2, p. 149-175, 2010. Disponível em: https:// www.emeraldinsight.com/doi/abs/10.1108/00330331011039508. Acesso em: 7 fev. 2019.

MIGUEL, Paulo Augusto Cauchick et al. Metodologia de pesquisa em engenharia de produção e gestão de operações. 2 ed. Rio de Janeiro: Elsevier, 2011.

MOHAMMED, M. N et al. Study on RFID Based Book Tracking and Library Information System. In: 2019 IEEE 15th International Colloquium on Signal Processing \& Its Applications (CSPA), 2019, Malaysia. Artigo [...]. IEEE, 2019. p. 235-238. Disponível em: https://ieeexplore.ieee.org/document/8696005. Acesso em: 6 fev. 2020.

MORESI, E. Metodologia da Pesquisa. Brasília: Universidade Católica de Brasília UCB, 2003. Disponível em: http://www.inf.ufes.br/ pdcosta/ensino/2010-2metodologia-depesquisa/MetodologiaPesquisa-Moresi2003.pdf. Acesso em: 20 mar. 2019.

NISHA, Faizul. Implementation of RFID Technology at Defence Science Library, DESIDOC : A Case Study. DESIDOC Journal of Library \& Information Technology, [s. I.], v. 38, n. 1 , p. 27-33, 2 jan. 2018. Disponível em: https://publications.drdo.gov.in/ojs /index.php/djlit/article/view/12351. Acesso em: 11 fev. 2019.

NOUDOOSTBENI, Ali; KAUR, Kiran; JENATABADI, Hashem Salarzadeh. A Comparison of Structural Equation Modeling Approaches with DeLone \& McLean's Model: A Case Study of Radio-Frequency Identification User Satisfaction in Malaysian University Libraries. Sustainability, [s. I.], v. 10, n. 7, p. 1-16, jul. 2018. Disponível em: https:// www.mdpi.com/2071-1050/10/7/2532. Acesso em: 14 mar. 2019.

RC: 94806

Disponível em:

https://www.nucleodoconhecimento.com.br/tecnologia/radiofrequencia-em- 
PUERTA, Adriana Aparecida et al. Avaliação do uso do serviço de autoatendimento com tecnologia RFID na Biblioteca da Unesp-Câmpus de Rio Claro. In: Anais do Congresso Brasileiro de Biblioteconomia, Documentação e Ciência da InformaçãoFEBAB. 2013. p. 1095-1105.

RAHMAN, Md. Habibur; ISLAM, Md. Shiful. Implementation of RFID in university libraries of Bangladesh. Global Knowledge, Memory and Communication, [s. I.], v. 68, n. 1/2, p. 112-124, 2019. Disponível em: https://www.emeraldinsight.com/doi/abs/10.1108/ GKMC-06-2018-0053. Acesso em: 25 fev. 2019.

RIBEIRO, Priscilla Cristina Cabral; SOUZA, Pedro. Análise do uso da RFID em bibliotecas públicas no Brasil. In: XXIV Simpósio de Engenharia de Produção, nov. 2017, Bauru, SP. Artigo [...]. . Disponível em: https://www.researchgate.net/publication/321675810_ANALISE_DO_USO_DA_RFID _EM_BIBLIOTECAS_PUBLICAS_NO_BRASIL. Acesso em: 14 jul. 2020.

SANTOS, Jonathan Pinheiro dos. Tecnologia de identificação por radiofrequência (RFID) em acervos bibliográficos: estudo de caso da Biblioteca da Câmara dos Deputados. 2013.

SENADO. Institucional | Biblioteca, 2020. Disponível em: $<$ https://www12.senado.leg.br/institucional/biblioteca>. Acesso em : 28/08/2020.

STJ. Biblioteca, $2020 . \quad$ Disponível em: <http://www.stj.jus.br/sites/portalp/Institucional/Educacao-e-cultura/Biblioteca>. Acesso em : 27/08/2020.

SILVEIRA, Nalin Ferreira da; VALMORBIDA, Willian. Processo de etiquetagem para implantação da tecnologia RFID na biblioteca do centro universitário Univates. Revista Digital de Biblioteconomia e Ciência da Informação, Campinas, SP, v. 14, n. 2, p. 334-347, 2 fev. 2016. Disponível em: 
https://periodicos.sbu.unicamp.br/ojs/index.php/rdbci/article/ view/8641634. Acesso em: 25 fev. 2019.

SUNIL, Mr.; OJHA, Nitish. Radio Frequency Identification (RFID) Technology in Library: Advantages and Issues In: 2nd International Conference on Inventive Systems and Control, 2018, Coimbatore. Artigo [...]. IEEE, 2018. p. 1206-1213. Disponível em: https://ieeexplore.ieee.org/document/8398996. Acesso em: 3 fev. 2019.

TIMOSHENKO, I. V. The Application of the Radio Frequency Identification Technology at Libraries: The Russian Experience. Scientific and Technical Information Processing, [s. I.], v. 43, n. 3, p. 189-193, 2016. Disponível em: https://link.springer.com/ article/10.3103/S0147688216030126. Acesso em: 18 mar. 2019.

UFLA. Biblioteca Universidade Federal de Lavras, 2020. Disponível em: $<$ http://biblioteca.ufla.br/site/index.php?option=com_content\&view=article\&id=6\&ltemi $d=187>$. Acesso em: 25/08/2020.

UNESP. Biblioteca, 2020. Disponível em: <https://www.bauru.unesp.br/\#!/biblioteca/sobre/historico/>. Acesso em: 26/08/2020

UNISINOS. Biblioteca Unisinos, 2020. Disponível em: <http://www.unisinos.br/biblioteca/a-biblioteca>. Acesso em: 27/08/2020.

UNIVERSIDADE FEEVALE. Biblioteca, 2020. Disponível em: $<$ https://www.feevale.br/institucional/biblioteca>. Acesso em: 28/08/2020.

VIANA, Michelângelo Mazzardo Marques. Uma breve história da automação de bibliotecas universitárias no Brasil e algumas perspectivas futuras. Revista IberoAmericana de Ciência da Informação, [s. I.], v. 9, n. 1, p. 43-86, 2016. Disponível em: http:// periodicos.unb.br/index.php/RICl/article/view/2187. Acesso em: 12 mar. 2019.

RC: 94806

Disponível em:

https://www.nucleodoconhecimento.com.br/tecnologia/radiofrequencia-embibliotecas 
YUSOF, Mohd Kamir; SAMAN, Md Yazid. The Adoption and Implementation of RFID: A Literature Survey. Library and Information Science Research e-journal, [s. I.], v. 26, n. 1, p. 31-52, 2016. Disponível em: https://www.libres-ejournal.info/2387/. Acesso em: 28 fev. 2019.

ZHOU, Donghua. Intelligent Library System Based on RFID Technology. Journal of Physics: Conference Series, [s. I.], v. 1345, 2019. Artigo [...]. Disponível em: https://iopscience.iop.org/article/10.1088/1742-6596/1345/4/042047/meta. Acesso em: 6 fev. 2020.

Enviado: Junho, 2021.

Aprovado: Agosto, 2021. 